\title{
TRAIL (TNF-Related Apoptosis-Inducing Ligand) Induces Necrosis-Like Cell Death in Tumor Cells at Acidic Extracellular pH
}

\author{
OLIVIER MEURETTE, LAURENCE HUC, AMELIE REBILLARD, \\ GWENAELLE LE MOIGNE, DOMINIQUE LAGADIC-GOSSMANN, AND \\ MARIE-THERESE DIMANCHE-BOITREL \\ INSERM U620, Faculté de Pharmacie, Université de Rennes 1, \\ 35043 Rennes cedex, France
}

\begin{abstract}
How tumor microenvironment, more specifically low extracellular pH (6.5), alters cell response to TNF-related apoptosis-inducing ligand (TRAIL)-based cancer therapy has yet to be determined. The aim of the current work was to test the effect of acidic extracellular $\mathrm{pH}$ on TRAIL-induced cell death in human HT29 colon carcinoma and HepG2 hepatocarcinoma cell lines as well as in human primary hepatocytes. We found an increase in TRAIL sensitivity at low extracellular $\mathbf{p H}$, which is partially inhibited by Bcl-2 expression in HT29 cells. At low extracellular pH, TRAIL induced a new form of cell death, sharing necrotic and apoptotic features in tumor cells. By contrast, human primary hepatocytes were resistant to TRAIL-induced cell death even at acidic extracellular pH.
\end{abstract}

KEYWORDS: TRAIL; pH; apoptosis; necrosis; hepatocarcinoma cells; colon cancer cells; human primary hepatocytes

\section{INTRODUCTION}

TRAIL (TNF- $\alpha$ related apoptosis-inducing ligand) is a cytokine belonging to the tumor necrosis factor (TNF)- $\alpha$ superfamily and a promising anticancer agent. In fact, TRAIL induces apoptosis in many cancer cells but not in most normal cells. ${ }^{1}$ Moreover, TRAIL administration in nude or SCID mice reduces growth of colon carcinoma or mammary adenocarcinoma xenografts without any toxic effects. ${ }^{1,2}$

Apoptosis is a genetically regulated cell death that plays an essential role in development, tissue homeostasis, and elimination of damaged cells. Disruption of molecular mechanisms controlling apoptosis can lead to oncogenesis and chemoresistance of transformed cells. Two main apoptotic pathways leading to caspase activation have been characterized: the intrinsic mitochondria-mediated pathway ${ }^{3}$ and the extrinsic death receptor-mediated pathway. ${ }^{4}$ TRAIL-mediated cell death

Address for correspondence: Marie-Therese Dimanche-Boitrel, INSERM U620, Faculté de Pharmacie, Université Rennes 1, 2 av Prof Léon Bernard, 35043 Rennes cedex, France. Voice: (33)2.23.23.48.37; fax: (33)2.23.23.47.94.

marie-therese.boitrel@rennes.inserm.fr

Ann. N.Y. Acad. Sci. 1056: 379-387 (2005). () 2005 New York Academy of Sciences.

doi: 10.1196/annals.1352.018 
occurs essentially through activation of the death receptor apoptotic pathway and involves interaction of the intracytoplasmic death domain of TRAIL receptors (TRAIL-R1 [DR4] and TRAIL-R2 [DR5]) with the adaptor molecule FADD (Fasassociated death domain). In turn, FADD recruits procaspase- 8 to form the DISC (death-inducing signaling complex), in which caspase-8 is activated by autoproteolysis, and initiates the proteolytic caspase cascade that triggers activation of downstream effector caspases. Two complementary pathways were shown to lead to apoptosis following caspase- 8 activation. ${ }^{5}$ The first one, in which caspase- 8 directly activates caspase-3, does not involve the mitochondria and escapes the resistance mediated by overexpression of Bcl-2 and related antiapoptotic proteins. The second pathway involves the cleavage of $\mathrm{Bid}$, a $\mathrm{BH} 3$-domain-only proapoptotic protein that belongs to the Bcl-2 family. ${ }^{6}$ The truncated Bid (tBid) induces mitochondrial changes, including the translocation of proapoptotic proteins such as cytochrome $c$, Smac/ DIABLO, and apoptosis-inducing factor (AIF), from the mitochondria to either cytosol, where they activate the caspase cascade, or to nucleus, where they trigger DNA fragmentation and chromatin condensation. ${ }^{6,7}$ This second pathway is inhibited by Bcl-2 and related antiapoptotic proteins.

All cancer cells, however, are not sensitive to TRAIL, and several molecular mechanisms have been described to explain this resistance. ${ }^{8}$ Moreover, how TRAIL efficacy is modulated in the context of tumor microenvironment remains poorly understood. A high rate of glycolytic metabolism frequently induces high proton production, which contributes to acidification of the extracellular environment. ${ }^{9}$ Furthermore, intracellular $\mathrm{pH}$ might be an important regulator of cell death. ${ }^{10}$ In the current work, we lowered the extracellular $\mathrm{pH}$ to a value of 6.5 in HT29 and HepG2 cells as well as in normal human primary hepatocytes to study the effect of such a maneuver on cell sensitivity to TRAIL-induced cell death. The effect of Bcl-2 expression in HT29 cells was also investigated in response to TRAIL-induced cell death at low extracellular $\mathrm{pH}$.

\section{MATERIAL AND METHODS}

\section{Chemicals and Antibodies}

The recombinant human soluble Flag-tagged TRAIL was from Alexis Biochemicals (Coger, Paris, France; http://www.alexis-corp.com). The anti-Flag M2 was from Sigma-Aldrich (Saint-Quentin Fallavier, France). The anti-Flag M2 was used to crosslink the ligand TRAIL, leading to the formation of oligomers that are more effective in inducing cell death. Briefly, increased concentrations of the soluble Flag-tagged TRAIL were incubated with $2 \mu \mathrm{g} / \mathrm{ml}$ anti-Flag M2 for 5 minutes at room temperature before cell treatment. The pan-caspase inhibitor (z-VAD-fmk), the caspase-8 inhibitor (z-IETD-fmk), and the caspase inhibitor negative control (z-FAfmk) were from Calbiochem (France Biochem, Meudon, France). Antagonistic mouse monoclonal antibodies directed against the extracellular domain of human TRAIL-R1 (DR4) and TRAIL-R2 (DR5) were from Alexis Biochemicals. The antagonistic mouse monoclonal antibody directed against the Fas receptor (ZB4) was from Immunotech (Coulter, Marseille, France). 


\section{Cell Lines and Cytotoxic Assay}

The HT29 human colon carcinoma cell line and the HepG2 human hepatocarcinoma cell line were obtained from ATCC (Rockville, MD, USA) and cultured in Eagle's minimum essential medium (Eurobio, Les Ulis, France) or Williams E medium (GibcoBRL, Life Technologies, Cergy Pontoise, France), respectively, supplemented with $10 \%$ (v/v) fetal calf serum (GibcoBRL), glutamine (2 mM; HT29 and HepG2), and bovine serum albumin $(0.1 \mathrm{mg} / \mathrm{ml})$, bovine insulin $(1 \mu \mathrm{g} / \mathrm{ml})$, and hydrocortisone $\left(0.25 \mu \mathrm{g} / \mathrm{ml}\right.$; HepG2) at $37^{\circ} \mathrm{C}$ under a $5 \% \mathrm{CO}_{2}$ atmosphere. The HT29 neo/Bcl-2 cells were previously described. ${ }^{11}$

Microscopic detection of apoptosis or necrosis was carried out in both floating and adherent cells recovered after TRAIL treatment using nuclear chromatin staining with $1 \mu \mathrm{g} / \mathrm{ml}$ Hoechst 33342 and $1 \mu \mathrm{g} / \mathrm{ml}$ propidium iodide (PI) for 15 minutes at $37^{\circ} \mathrm{C}$. Apoptotic cells (i.e., those with condensed blue chromatin or fragmented blue nuclei) or necrotic cells (i.e., those with red nuclei) were counted and compared with those of the total population ( $n=300$ cells).

\section{Primary Human Hepatocyte Cultures and Cytotoxic Assay}

Human hepatocytes from adult donors undergoing resection for primary and secondary tumors were obtained by perfusion using a collagenase solution as described previously. ${ }^{12}$ Cells were seeded at a density of $3 \times 10^{4}$ cells $/ \mathrm{cm}^{2}$ in Williams E medium supplemented with glutamine $(2 \mathrm{mM})$, bovine serum albumin $(0.2 \mathrm{mg} / \mathrm{ml})$, bovine insulin $(10 \mu \mathrm{g} / \mathrm{ml})$, and $10 \%(\mathrm{v} / \mathrm{v})$ fetal calf serum. The next day, hydrocortisone $\left(10^{-7} \mathrm{M}\right)$ was added. Hepatocytes from six adult donors were isolated, and treatments were performed in triplicate under the same conditions as just described for human cancer cell lines.

\section{Modification of Extracellular pH $\left(\mathrm{pH}_{e}\right)$ and Measurement of Intracellular $\mathrm{pH}\left(\mathrm{pH}_{i}\right)$}

To modify the value of extracellular $\mathrm{pH}$, a growth medium without sodium hydrogenocarbonate was used. To set the extracellular $\mathrm{pH}$ of this medium to either 7.4 or 6.5 , we supplemented it with $23 \mathrm{mM}$ or $3 \mathrm{mM}$ sodium hydrogenocarbonate, respectively, in an atmosphere of $5 \% \mathrm{CO}_{2}$. The $\mathrm{pH}_{\mathrm{i}}$ of cells cultured on glass coverslips was monitored with the $\mathrm{pH}$-sensitive fluorescent probe carboxy-SNARF-1 (carboxyseminaphtorhodafluor; Molecular Probes, Invitrogen, Cergy-Pontoise, France) ${ }^{13}$ Cells were loaded with SNARF by incubating them in a $5-\mu \mathrm{M}$ solution of the acetoxy-methyl ester for 20 minutes at $37^{\circ} \mathrm{C}$ just prior to recording $\mathrm{pH}_{\mathrm{i}}$. SNARF-loaded cells were placed in a continuously perfused recording chamber (at a temperature of $37 \pm 1^{\circ} \mathrm{C}$ ) mounted on the stage of an epifluorescent microscope (Nikon Diaphot). The necessary setup to produce and detect fluorescence has previously been described. ${ }^{14}$ The emission ratio 640/590 (corrected for background fluorescence) detected from intracellular SNARF was calculated and converted to a linear $\mathrm{pH}$ scale using in situ calibration obtained by the nigericin technique described elsewhere. ${ }^{13}$ 


\section{RESULTS}

Extracellular $\mathrm{pH}$ is lower in tumor than in normal tissue due to the intense glycolytic activity of cancer cells, whereas intracellular $\mathrm{pH}$ is little, if not affected. This gives rise to a cellular transmembrane $\mathrm{pH}$ gradient difference between these tissues with a tumor-specific $\mathrm{pH}$ gradient that might enhance the cytotoxicity of chemotherapeutics. ${ }^{15}$ To verify that such a gradient exists under our experimental conditions, we first measured the intracellular $\mathrm{pH}$ when cells were cultured in an acidic extracellular medium. We observed a decrease of about $0.2 \mathrm{pH}$ unit of the intracellular $\mathrm{pH}$ in HT29 and HepG2 cell lines cultured at $\mathrm{pH}_{\mathrm{e}} 6.5$ (FIG. 1A), which clearly indicated an increase in the transmembrane $\mathrm{pH}$ gradient. We then studied the effect of such a modification on cell sensitivity to TRAIL-induced cell death. HT29 and HepG2 cells that were initially resistant became very sensitive following a 24-hour treatment with TRAIL at low extracellular pH (FIG. 1B). Surprisingly, the dead cells did not exhibit the typical apoptotic morphology with condensed blue chromatin and/or fragmented blue nuclei observed when cells were treated with TRAIL at normal (7.4) extracel-

A
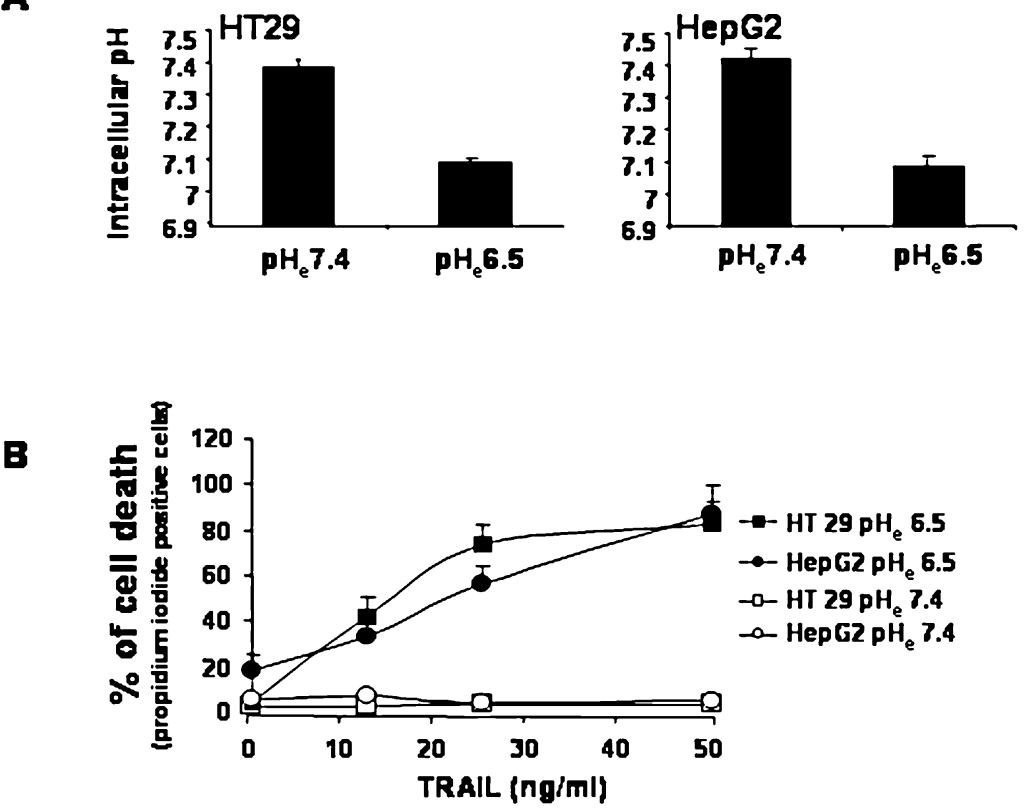

FIGURE 1. TRAIL treatment induces necrosis-like cell death in HT29 and HepG2 cells at acidic extracellular $\mathrm{pH}$ (6.5). (A) Intracellular $\mathrm{pH}$ values were determined by microspectrofluorimetry using a carboxy-SNARF-1-AM at normal (7.4) and acidic (6.5) extracellular pH in HT29 and HepG2 cells as described in Material and Methods. (B) Cells were exposed to increased concentrations of TRAIL $(12.5,25$, and $50 \mathrm{ng} / \mathrm{ml}$ crosslinked with $2 \mu \mathrm{g} / \mathrm{ml}$ anti-Flag M2) for $24 \mathrm{~h}$ at normal (7.4) or acidic (6.5) extracellular $\mathrm{pH}$ before identifying dead cells by staining nuclear chromatin with Hoechst 33342 and propidium iodide. Three hundred cells per point were counted. The percentage of necrotic cell deaths was estimated as the percentage of propidium iodide-positive cells. Results are the mean \pm SD of three independent experiments. 
lular pH (approximately $15 \%$ of apoptotic cells in HT29 cells treated with TRAIL [50 ng/ml] for 24 hours at $\mathrm{pH}_{\mathrm{e}} 7.4$; data not shown). Indeed, they underwent an early plasma membrane permeabilization to propidium iodide, which is a common feature of necrosis (approximately $80 \%$ of necrotic cells in HT29 cells treated with TRAIL [50 ng/ml] for 24 hours at $\mathrm{pH}_{\mathrm{e}} 6.5$; FIG. 1B). Nevertheless, this cell death was dependent on caspase activation since a pan-caspase inhibitor (z-VAD-fmk) or a caspase-8 inhibitor (z-IETD-fmk) blocked TRAIL-induced cell death at low extracellular pH in HT29 cells (FIG. 2A). The caspase inhibitor negative control (z-FAfmk) had no effect on TRAIL-induced cell death at $\mathrm{pH}_{\mathrm{e}} 6.5$ (FIG. 2A). To determine
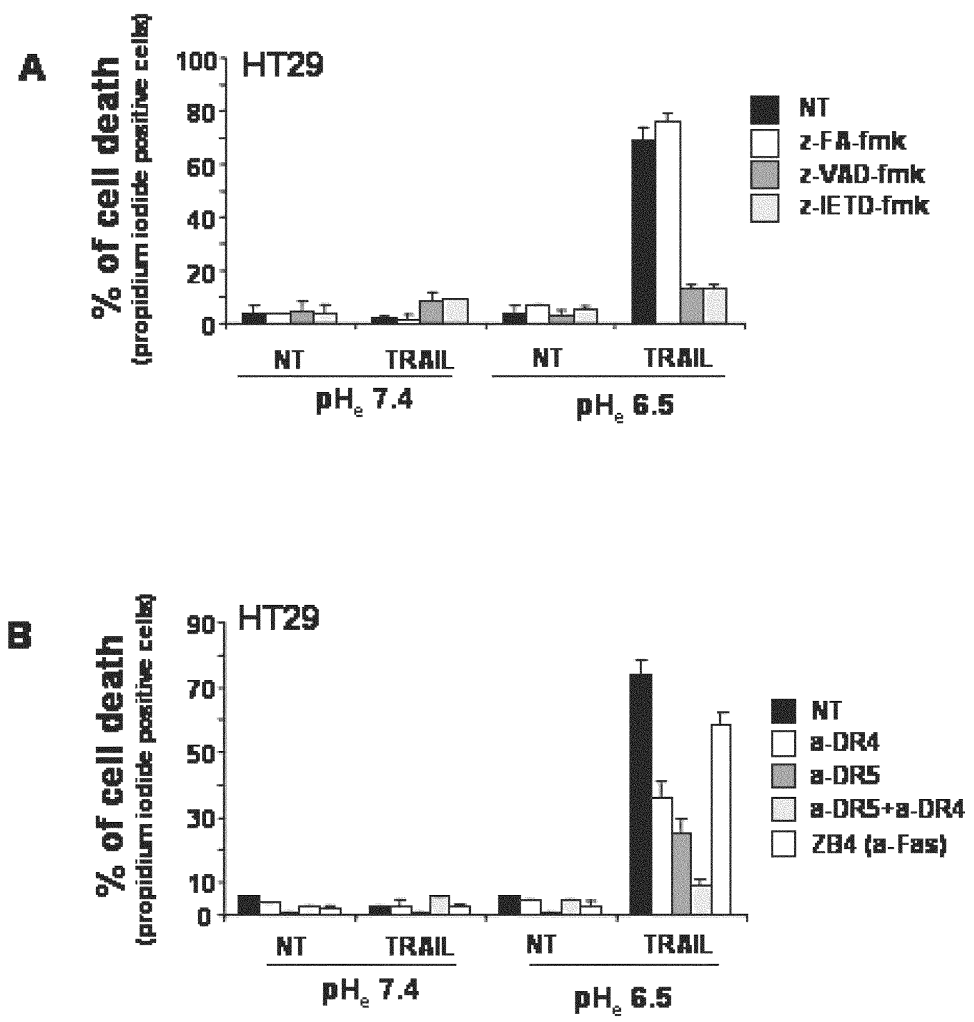

FIGURE 2. TRAIL-induced cell death at acidic extracellular $\mathrm{pH}$ depends on caspase activation and on TRAIL death receptor (DR4 and DR5) pathway. (A) HT29 cells were treated for $24 \mathrm{~h}$ with TRAIL (50 $\mathrm{ng} / \mathrm{ml}$ crosslinked with $2 \mu \mathrm{g} / \mathrm{ml}$ anti-Flag M2) at normal (7.4) or acidic (6.5) extracellular $\mathrm{pH}$ in the presence or absence of caspase inhibitors z-VAD-fmk and z-IETD-fmk, at a concentration of $10 \mu \mathrm{M}$, respectively. Z-FA-fmk $(10 \mu \mathrm{M})$ was used as a caspase inhibitor negative control. (B) HT29 cells were treated for $24 \mathrm{~h}$ with TRAIL (50 $\mathrm{ng} / \mathrm{ml}$ crosslinked with $2 \mu \mathrm{g} / \mathrm{ml}$ anti-Flag M2) at normal (7.4) or acidic (6.5) extracellular $\mathrm{pH}$ in the presence or absence of antagonistic antibodies anti-DR4 $(10 \mu \mathrm{g} / \mathrm{ml})$ and/or anti-DR5 $(10 \mu \mathrm{g} / \mathrm{ml})$. An antagonistic anti-Fas receptor antibody (ZB4, $10 \mu \mathrm{g} / \mathrm{ml})$ was used as a negative control. In $\mathbf{A}$ and $\mathbf{B}$, the percentage of cell deaths was estimated as the percentage of propidium iodide positive cells as described in FIGURE 1. Results are the mean \pm SD of three independent experiments. 
if this cell death pathway was dependent on TRAIL death receptors, we used antagonistic antibodies directed against TRAIL-R1 (DR4) or TRAIL-R2 (DR5). Both DR4 and DR5 were required for TRAIL-induced cell death at an acidic extracellular $\mathrm{pH}$ because a combination of antagonistic antibodies directed against the extracellular domain of each receptor was necessary to completely inhibit TRAIL-mediated cell death in HT29 cells, whereas only partial inhibition was observed when either antibody was used alone (FIG. 2B). When an antagonistic antibody directed against a Fas receptor (ZB4) was used as a negative control, no effect on TRAIL-induced cell death at low extracellular pH was detected (FIG. 2B). As an acidic extracellular $\mathrm{pH}$ is usually a specific characteristic of tumor microenvironment, we tested the sensitivity of normal human primary hepatocytes to TRAIL-induced cell death under acidic extracellular conditions. Under these experimental conditions, normal human primary hepatocytes remained resistant to TRAIL-induced cell death (FIG. 3), sug-

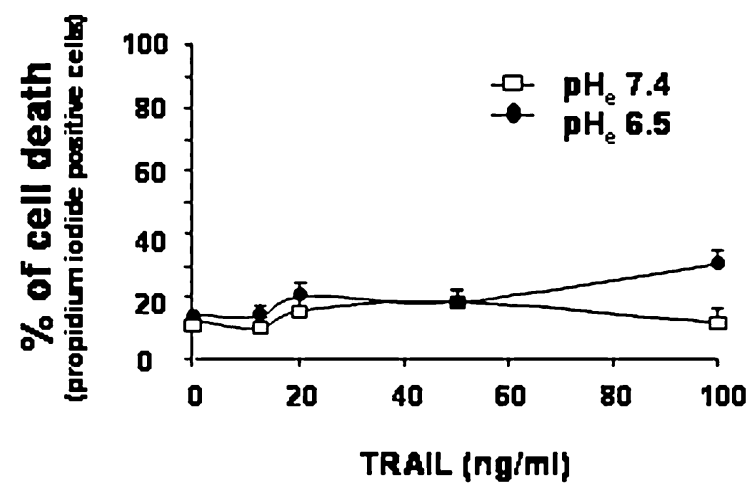

FIGURE 3. TRAIL is not cytotoxic towards human primary hepatocytes even at acidic extracellular pH. Human primary hepatocytes were treated as in FIGURE 1B, and the percentage of cell deaths was estimated as the percentage of propidium iodide-positive cells. Results are the mean \pm SD of six independent experiments.

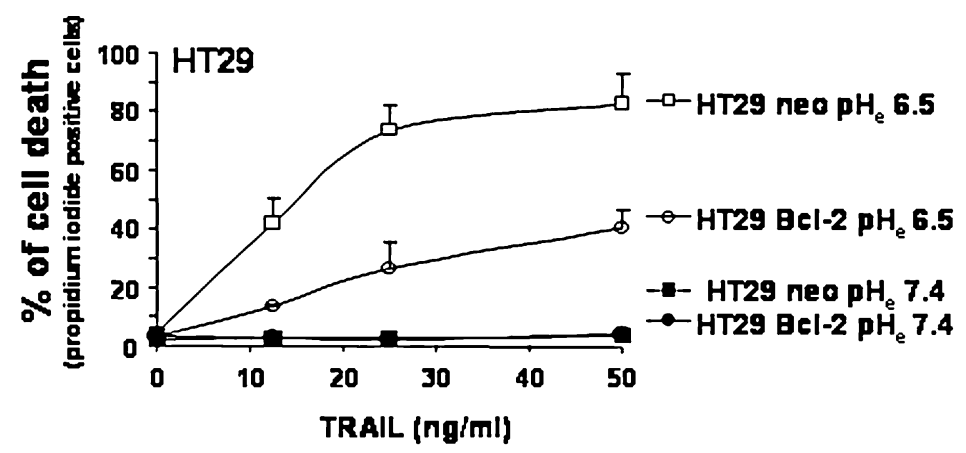

FIGURE 4. Bcl-2 expression in HT29 cells delays TRAIL-induced cell death at acidic extracellular pH. HT29 neo/Bcl-2 cells are treated as in FIGURE 1B, and the percentage of cell deaths was estimated as the percentage of propidium iodide-positive cells. Results are the mean \pm SD of three independent experiments. 
gesting that normal cells even in the close tumor microenvironment should not be sensitive to TRAIL-induced cell death. Finally, the effect of Bcl-2 expression on TRAIL-induced cell death at a low extracellular $\mathrm{pH}$ was investigated in HT29 cells. We demonstrated that Bcl-2 expression delayed this cell death (FIG. 4), thus indicating that $\mathrm{Bcl}-2$ might be a resistant factor towards this cell death pathway.

\section{DISCUSSION}

An acidic extracellular $\mathrm{pH}$ is a characteristic of numerous solid tumors. ${ }^{9}$ Furthermore, the tumor-specific $\mathrm{pH}$ gradient could play an important role in chemosensitivity. ${ }^{16,17}$ We show here that an acidic extracellular environment led to a high sensitization to TRAIL-induced cell death in human colon carcinoma and hepatocarcinoma cells. Our data agree with the observations of Lee et al. ${ }^{18}$ who showed that human prostate carcinoma cells could be sensitized to TRAIL-induced apoptosis under an acidic extracellular $\mathrm{pH}$. Surprisingly, under our experimental conditions, this cell death appeared not to be apoptotic. In fact, the plasma membrane was permeabilized early, and the chromatin was not fragmented, pointing to a necrosis-like cell death. Interestingly, we observed that TRAIL-induced cell death at low extracellular $\mathrm{pH}$ was blocked by caspase inhibitors (z-IETD-fmk or z-VAD-fmk), thus suggesting that caspases, more specifically caspase-8, are necessary to this particular cell death pathway. Such caspase- 8 involvement has also been described in necrotic cell death of human lung adenocarcinoma A549 cells exposed to hyperoxia. ${ }^{19}$ Furthermore, Bcl-2 expression in HT29 cells appeared to delay TRAIL-induced cell death at low extracellular $\mathrm{pH}$, suggesting that mitochondria might be involved in this process. An increased interaction between t-Bid and Bax has been correlated with the increase in TRAIL sensitivity under acidic extracellular conditions in human colorectal carcinoma CX-1 cells, also indicating a role of the mitochondrial death pathway. ${ }^{18}$ In this regard, it is worth noting that the antiapoptotic members of the Bcl-2 superfamily have been shown to inhibit both necrosis and apoptosis. ${ }^{20}$ Recently, in prostate adenocarcinoma cells, TRAIL treatment was reported to induce a necrosis process insensitive to a pan-caspase inhibitor (z-VAD-fmk). ${ }^{21}$ In the same way, a necrotic death pathway independent of caspase activation has been described after triggering other death receptors, such as TNFR1 or Fas. ${ }^{22,23}$ Necrosis has long been considered an accidental cell death as opposed to programmed cell death, apoptosis. However, it appears now that multiple programmed cell death pathways exist, ${ }^{24,25}$ and necrosis appears to be part of those playing a role in embryogenesis, normal tissue renewal, and immune response. ${ }^{20}$ In this regard, it is also noteworthy that the inflammatory response caused by necrosis may activate an innate immune response under some pathologic conditions such as cancer. ${ }^{20}$ This point is important to emphasize because, depending on the extent of such a response, necrosis could improve the efficacy of chemotherapy by activating an anticancer cell immune response. Currently, the molecular mechanisms involved in TRAIL-induced cell death at acidic extracellular $\mathrm{pH}$ are under investigation. In fact, it is of clinical relevance to understand how this cell death pathway occurs after TRAIL treatment in vivo. We also showed that human primary hepatocytes were not sensitized to TRAIL-induced cell death under acidic conditions, suggesting that targeting cellular $\mathrm{pH}$ could be a potential approach to selectively sensitizing tumor cells to TRAIL- 
based cancer therapy. In this regard, cellular $\mathrm{pH}$ has been considered a promising molecular target for cancer chemotherapy. ${ }^{26}$ However, Bcl-2 might be an important resistant factor.

\section{ACKNOWLEDGMENTS}

We thank the Biological Resource Centre (BRC) of Rennes for supplying of isolated human primary hepatocytes. We also thank the Ligue Nationale Contre le Cancer (the Morbihan, Côte d'Armor, and Ille et Vilaine Committees), Rennes Métropole, and the Région Bretagne for their financial support.

\section{REFERENCES}

1. Ashrenazi, A., R.C. PaI, S. Fong, et al. 1999. Safety and antitumor activity of recombinant soluble Apo2 ligand. J. Clin. Invest. 104: 155-162.

2. WalczaK, H., R.E. Miller, K. Ariail, et al. 1999. Tumoricidal activity of tumor necrosis factor-related apoptosis- inducing ligand in vivo. Nat. Med. 5: 157-163.

3. Zimmermann, K.C. \& D.R. Green. 2001. How cells die: apoptosis pathways. J. Allergy Clin. Immunol. 108: S99-103.

4. AshKenAzI, A. 2002. Targeting death and decoy receptors of the tumour-necrosis factor superfamily. Nat. Rev. Cancer 2: 420-430.

5. Scaffidi, C., S. Fulda, A. SRInivasan, et al. 1998. Two CD95 (APO-1/Fas) signaling pathways. Embo J. 17: 1675-1687.

6. LI, H., H. ZhU, C.J. XU, et al. 1998. Cleavage of BID by caspase 8 mediates the mitochondrial damage in the Fas pathway of apoptosis. Cell 94: 491-501.

7. Kroemer, G. \& J.C. Reed. 2000. Mitochondrial control of cell death. Nat. Med. 6: $513-519$.

8. ZHANG, L. \& B. FANG. 2005. Mechanisms of resistance to TRAIL-induced apoptosis in cancer. Cancer Gene Ther. 2: 228-237.

9. Wike-Hooley, J.L., A.P. van Den Berg, J. van Der Zee, et al. 1985. Human tumour pH and its variation. Eur. J. Cancer Clin. Oncol. 21: 785-791.

10. Lagadic-Gossmann, D., L. Huc \& V. Lecureur. 2004. Alterations of intracellular pH homeostasis in apoptosis: origins and roles. Cell Death Differ. 11: 953-961.

11. Lacour, S., O. Micheau, A. Hammann, et al. 2003. Chemotherapy enhances TNFrelated apoptosis-inducing ligand DISC assembly in HT29 human colon cancer cells. Oncogene 22: 1807-1816.

12. Guguen-Guillouzo, C., J.P. Campion, P. Brissot, et al. 1982. High yield preparation of isolated human adult hepatocytes by enzymatic perfusion of the liver. Cell Biol. Int. Rep. 6: 625-628.

13. BuCKLER, K.J. \& R.D. Vaughan-Jones. 1990. Application of a new pH-sensitive fluoroprobe (carboxy-SNARF-1) for intracellular $\mathrm{pH}$ measurement in small, isolated cells. Pflugers Arch. 417: 234-239.

14. Lagadic-Gossmann, D., M. Rissel, M. Galisteo, et al. 1999. Intracellular pH alterations induced by tacrine in a rat liver biliary epithelial cell line. Br. J. Pharmacol. 128: $1673-1682$.

15. Kozin, S.V., P. ShKarin \& L.E. Gerweck. 2001. The cell transmembrane pH gradient in tumors enhances cytotoxicity of specific weak acid chemotherapeutics. Cancer Res. 61: 4740-4743.

16. TANnOCK, I.F. \& D. Rotin. 1989. Acid pH in tumors and its potential for therapeutic exploitation. Cancer Res. 49: 4373-4384.

17. Raghunand, N. \& R.J. Gillies. 2001. pH and chemotherapy. Novartis Found. Symp. 240: 199-211; discussion 265-198. 
18. LeE, Y.J., J.J. Song, J.H. KIM, et al. 2004. Low extracellular pH augments TRAILinduced apoptotic death through the mitochondria-mediated caspase signal transduction pathway. Exp. Cell Res. 293: 129-143.

19. WANG, X., S.W. RYTER, C. Dai, et al. 2003. Necrotic cell death in response to oxidant stress involves the activation of the apoptogenic caspase-8/bid pathway. J. Biol. Chem. 278: 29184-29191.

20. Proskuryakov, S.Y., A.G. Konoplyannikov \& V.L. Gabai. 2003. Necrosis: a specific form of programmed cell death? Exp. Cell Res. 283: $1-16$.

21. KemP, T.J., J.S. KIM, S.A. CRIST, et al. 2003. Induction of necrotic tumor cell death by TRAIL/Apo-2L. Apoptosis 8: 587-599.

22. Denecker, G., D. Vercammen, W. DeclercQ, et al 2001. Apoptotic and necrotic cell death induced by death domain receptors. Cell Mol. Life Sci. 58: 356-370.

23. Holler, N., R. ZARU, O. Micheau, et al. 2000. Fas triggers an alternative, caspase-8independent cell death pathway using the kinase RIP as effector molecule. Nat. Immunol. 1: 489-495.

24. JaAttela, M. 2004. Multiple cell death pathways as regulators of tumour initiation and progression. Oncogene 23: 2746-2756.

25. Leist, M. \& M. JaAtTEla. 2001. Four deaths and a funeral: from caspases to alternative mechanisms. Nat. Rev. Mol. Cell Biol. 2: 589-598.

26. Izumi, H., T. Torigoe, H. Ishiguchi, et al. 2003. Cellular pH regulators: potentially promising molecular targets for cancer chemotherapy. Cancer Treat. Rev. 29: 541549. 